\title{
Postgastrectomy protein-losing cytomegalovirus jejunitis in an immunocompromised patient
}
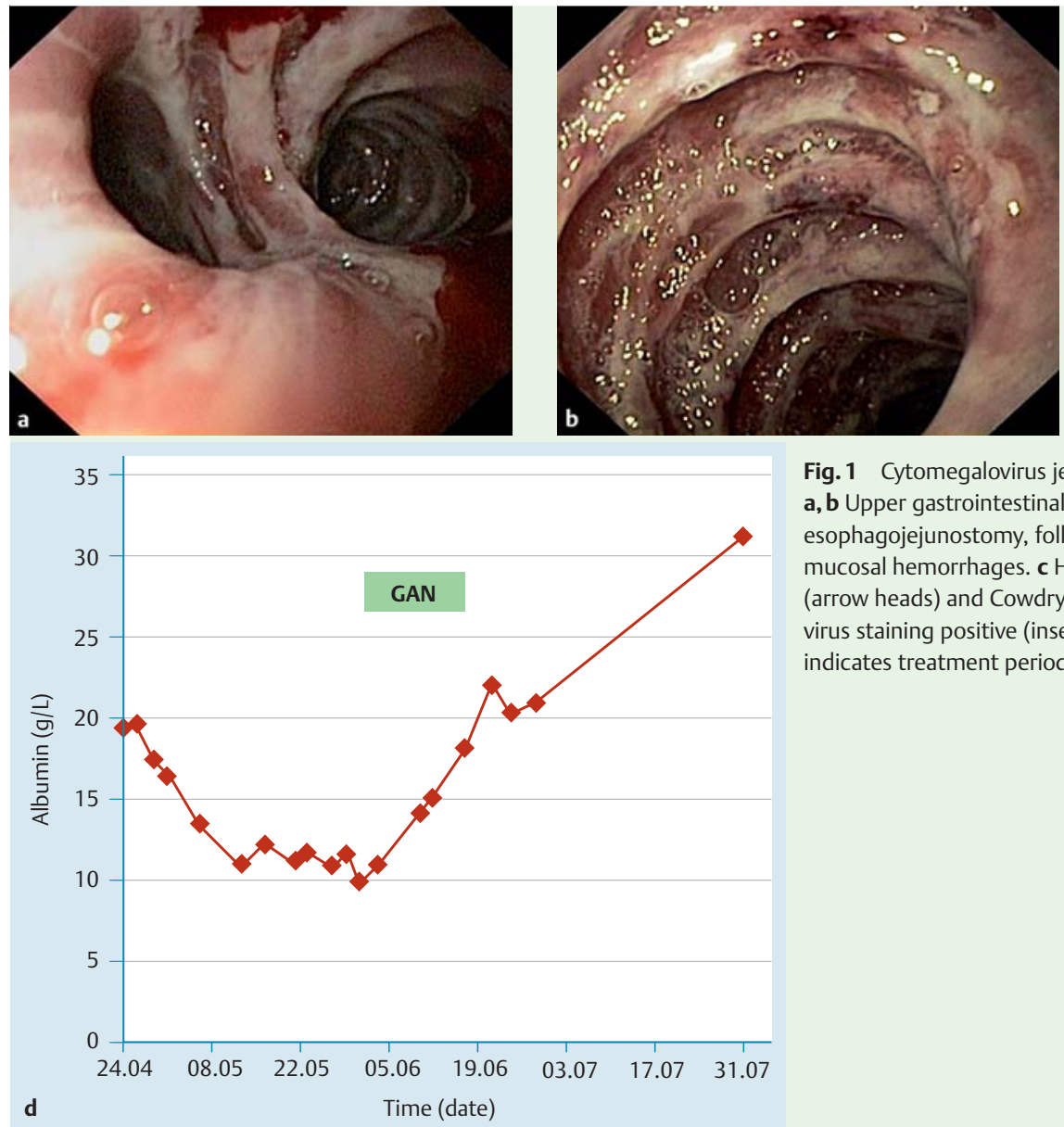

Fig. 1 Cytomegalovirus jejunitis in an immunocompromised patient. a, b Upper gastrointestinal endoscopy revealed inflamed mucosa from the esophagojejunostomy, followed by ulcerative jejunitis with spontaneous submucosal hemorrhages. $\mathbf{c}$ Hematoxylin and eosin staining showed cytomegaly (arrow heads) and Cowdry inclusion body (arrow), with specific cytomegalovirus staining positive (insert). $\mathbf{d}$ Serum albumin levels over time. Green bar indicates treatment period with ganciclovir.
A 59-year-old man was admitted because of nausea and fatigue. He had been diagnosed with gastric adenocarcinoma 7 months earlier, and because of gastric outlet obstruction had undergone total gastrectomy with esophagojejunostomy and omentectomy $\left(\mathrm{pT}_{3} \mathrm{~N}_{3 \mathrm{~b}} \mathrm{M}_{0} \mathrm{R}_{1}\right)$. Postoperatively, platinum-based chemotherapy was initiated, followed by radiochemotherapy (5-fluorouracil + 45 Gy) approximately 2 weeks before admission. Initially, the nausea and fatigue were attributed to ongoing radiochemotherapy. During admission the patient became bedbound, with pronounced anasarca edema secondary to severe hypoalbuminemia (lowest level 9.9g/L, normal 35-52 g/L) despite maximal supportive care, suggestive of protein-losing enteropathy (proteinuria was only mild). From the esophagojejunostomy onwards, the mucosa was severely inflamed with ulcerations, desquamation, and spontaneous submucosal hemorrhages for approximately $15 \mathrm{~cm}$ in the jejunum ( Fig.1a,b). Microscopic examination revealed extensive ulceration with granulation and dense infiltration of mononuclear cells, cytomegaly, and Cowdry inclusions ( $\bullet$ Fig.1c). The diagnosis of cytomegalovirus (CMV) jejunitis was strengthened by positive serum CMV polymerase chain reaction (PCR; 3.84 log copies $/ \mathrm{mL}$ ). After 2 weeks of treatment with ganciclovir, the patient's general condition recovered and CMV PCR became negative. At 1 month after discharge, the patient was in good general condition with an albumin level of $31.2 \mathrm{~g} / \mathrm{L}(\bullet$ Fig. $1 \mathrm{~d}$ ).

Although CMV infection is mostly asymptomatic or gives rise to only mild mononucleosis-like symptoms, in immunocompromised or critically ill patients it can cause life-threatening complications [13]. CMV enteritis occurs in only $4 \%$ of patients with CMV disease and is mostly restricted to a defined area rather than being panenteric [4]. As shown in inflammatory bowel diseases where CMV infects areas of already inflamed mucosa [5], it is likely that mucosal changes secondary to radiotherapy provide favorable conditions for CMV infection. The protein-losing enteropathy was most likely a combination of inflammatory exudation and villous atrophy with increased permeability associated with CMV infection [6].

This case illustrates that CMV should be included in the differential diagnosis of protein-losing enteropathy, especially following radiation therapy, and that biopsies should be taken to investigate CMV even when other potential explanations of mucositis are present. 


\section{Endoscopy_UCTN_Code_CCL_1AC_2AH}

\section{Competing interests: None}

\section{Philip Roelandt ${ }^{1}$, Helene Poels ${ }^{1}$, Ester Meeus ${ }^{2}$, Eric Van Cutsem ${ }^{3}$, Hans Prenen ${ }^{3}$}

${ }^{1}$ Gastroenterology Department, University Hospitals Leuven, Leuven, Belgium

2 Pathology Department, University Hospitals Leuven, Leuven, Belgium

${ }^{3}$ Digestive Oncology Department, University Hospitals Leuven, Leuven, Belgium

\section{References}

1 Whitley RJ, Jacobson MA, Friedberg DN et al. Guidelines for the treatment of cytomegalovirus diseases in patients with AIDS in the era of potent antiretroviral therapy: recommendations of an international panel. International AIDS Society - USA. Arch Intern Med 1998; 158: 957-969

2 Chamberlain RS, Atkins S, Saini $N$ et al. Ileal perforation caused by cytomegalovirus infection in a critically ill adult. J Clin Gastroenterol 2000; 30: 432-435

3 Jain M, Duggal S, Chugh TD. Cytomegalovirus infection in non-immunosuppressed critically ill patients. J Infect Dev Ctries 2011; 5: 571-579

4 Baroco AL, Oldfield EC. Gastrointestinal cytomegalovirus disease in the immunocompromised patient. Curr Gastroenterol Rep 2008; 10: 409-416

5 Kaufman HS, Kahn AC, Iacobuzio-Donahue C et al. Cytomegaloviral enterocolitis: clinical associations and outcome. Dis Colon Rectum 1999; 42: 24-30

6 Nakase H, Itani T, Mimura J et al. Transient protein-losing enteropathy associated with cytomegalovirus infection in a noncompromised host: a case report. Am J Gastroenterol 1998; 93: 1005-1006

\section{Bibliography}

DOI http://dx.doi.org/

10.1055/s-0034-1377433

Endoscopy 2014; 46: E427-E428

(c) Georg Thieme Verlag KG

Stuttgart · New York

ISSN 0013-726X

\section{Corresponding author}

\section{Philip Roelandt, MD, PhD}

Gastroenterology Department

University Hospitals Leuven

Herestraat 49

3000 Leuven

Belgium

Fax: +32-16-344387

Philip.roelandt@uzleuven.be 